\title{
STUDY ON USERS ATTITUDE OF DIGITAL LIBRARY IN ENGINEERING COLLEGE, COIMBATORE
}

\author{
Dr. S. Aravind1, Dr. R. Kavitha ${ }^{2}$ \\ ${ }^{1}$ Librarian and Head, \\ Central Library $\mathcal{E}$ Department of Library and Information Science, \\ G.T.N. Arts College (Autonomous), Dindigul, Tamilnadu, India. \\ Email:aragtn2601@yahoo.com \\ ${ }^{2}$ Assistant Librarian \\ Mother Teresa Women's University Kodaikanal, India \\ Email :kavitharamalar@gmail.com
}

\section{Manuscript Info Abstract}

\section{Manuscript History}

Received: 09 October 2020

Final Accepted: 23 November 2020

Published: 10 December 2020

Online Published: January 2021

DOI: http:/ / dx.doi.org/10.35337/EIJLITR.2021.1102

Corresponding Author's E-mail:

aragtn2601@yahoo.com

kavitharamalar@gmail.com

(C) Dr. S. Aravind, Dr. R. Kavitha The Authors. This is an open access article under the terms of the Creative Commons Attribution License 4.0, which allows use, distribution and reproduction in any medium, provided the original work is properly cited.

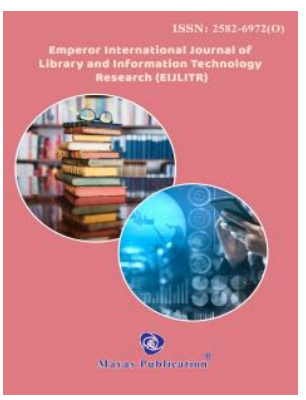

The current investigation intends to discover the examination on clients demeanor of advanced library in designing school, Coimbatore. An examples of 100 respondents chose arbitrarily were examined. Essential information were gathered by utilizing an organized meeting planned. All the respondents were posed the a few inquiries in a similar style and they were educated the reason regarding study. Spellbinding Statistics, Percentage examination, Independent Sample t-test and One ANOVA were applied to test the theories. The discoveries and perceptions are the outcome and result of the translations made during the investigation of examination.

Keywords: Users Attitude, Digital Library, Information Seeking Behavior, Net working and Demographic Variables

\section{INTRODUCTION}

The term Digital Library has an arrangement of likely ramifications, going from a digitized grouping of material that one may find in a standard library through to the combination of all serious information close by the organizations that make that information accommodating to each possible customer. As there are various implications of a "progressed library," terms, for instance, "electronic library" and "virtual library" are as often as possible used proportionately. A serious library is just a huge data base for 
the people who are managing hypertext atmosphere. It is an atmosphere, which supports the full life example of creation, storing, defending, spread and usage of data, information and data.

According to Arms an automated library is a managed variety of information with related organizations where the information is taken care of in cutting edge setup and accessible over an association. The modernized library partnership in the USA describes the serious library as: Digital libraries are affiliations that give the resources, including the particular staff, to pick, structure, offer academic induction to, translate, course, spare the reliability of, and ensure the inventiveness after some season of groupings of electronic works so they are instantly and financially available for use by a portrayed organization or set of organizations. A serious library is a planned collection of digitized material or it's holding in the automated structure, which can be open by a PC on the association by using TCP/IP or other show.

\section{REVIEW OF LITERATURE}

Tefko Saracevic, PhD (2017) study made by How were mechanized libraries surveyed, the plan is to offer an essential mix of takes a risk at cutting edge library appraisal that included data. In excess of 80 evaluation mulls over are penniless down as to appraisal: (1) forms, (2) setting, (3) measures and (4) techniques that were used. Approaches taken in appraisal considers are perceived and portrayed; a summary of creates is offered as to substances or cycles that were surveyed; setting or approaches taken in evaluation are recorded; different models used as a base of appraisal are orchestrated; in conclusion the frameworks used are recognized. Of the revelations only one is summarized: various customers experience issues in using automated libraries; a "versus" hypothesis is proposed portraying a poorly arranged association among customers and progressed libraries. Appraisal of modernized libraries isn't comprehensively penetrated. The corpus in this examination addresses a large portion of attempts in automated library appraisal that contain data. Finishes, among others, guess concerning the reasons behind a for the most part low presence of appraisal in cutting edge library assessment and practice.

Tefko Saracevic, Marija Dalbello (2018), An investigation of cutting edge library guidance In: Proceedings of the American Society for Information Science and Technology, study coordinated by electronic library has a couple of differentiating understandings, gotten from different organizations related with modernized library research, practice, affiliation, and exchange. Informative commitments followed these activities. The critical purpose of the paper is to present outcomes from a survey on the current status of automated library preparing in academic establishments. Notwithstanding, we in like manner review the thinking and heading for cutting edge library tutoring. We propose a couple of models that have emerged in the instructing of mechanized libraries and in combination of relevant focuses into various instructive projects.

Borgman (2018) gives an all the more astounding definition (checking an expansive discussion) of cutting edge libraries, a definition that may be considered as an augmentation between the assessment network definition and suitable organization definitions:

Progressed libraries are a lot of electronic resources and related specific capacities for making, looking, and using information. ... they are a growth and redesign of information amassing and recuperation circumstance that control progressed data in any medium ... The substance of mechanized libraries consolidates data, [and] metadata ... Digital libraries are constructed, accumulated, and facilitated, by (and for) an organization of customers, and their utilitarian capacities maintain the information needs and occupations of that organization.

\section{OBJECTIVES OF THE STUDY}

1. To know the customers' mien and reason about the Electronic library.

2. To understand the various sources used to cutting edge library.

3. To recognize the purpose behind social gathering information through cutting edge library.

4. To recognize the advantages and awful characteristics of cutting edge library. 


\section{METHODOLOGY}

A survey strategy was coordinated in electronic library of Engineering College, Coimbatore through the surveys. They were passed on by the method for unpredictable looking at. It is through the reviews, an undertaking has been made by the investigator to know the customers' air of cutting edge library. Almost 100 surveys were flowed to the picked respondents. The authority has winning concerning gathering 100 filled overviews, on which the assessment has been finished. The fundamental data for the examination were assembled by a strongly prepared pre-attempted survey. Meeting plan was moreover gotten by the investigator to gather the fundamental data.

\section{Limitation of the study}

The current assessment is confined to the libraries orchestrated in Engineering College, Coimbatore. Simply the customers who are attitude of mechanized library are pondered for the current assessment.

\section{Analysis and Discussions}

TABLE 1

SHOWING THE F/T-TEST FOR USERS ATTITUDE OF DIGITAL LIBRARY ON THE BASIS OF DEMOGRAPHIC VARIABLES

\begin{tabular}{|c|c|c|c|c|c|c|}
\hline Demographic variables & Sub Samples & $\mathbf{N}$ & Mean & SD & F/t-value & LS \\
\hline \multirow{2}{*}{ Gender } & Male & 65 & 72.22 & 5.21 & \multirow{2}{*}{2.95} & \multirow{2}{*}{0.05} \\
\hline & Female & 35 & 75.21 & 7.23 & & \\
\hline \multirow{3}{*}{ Age } & Up to 25 & 50 & 78.55 & 7.96 & \multirow{3}{*}{4.96} & \multirow{3}{*}{0.01} \\
\hline & $26-35$ & 32 & 72.39 & 4.69 & & \\
\hline & $36-45$ & 18 & 72.14 & 5.96 & & \\
\hline \multirow{5}{*}{ Designation } & Assistant Professor & 40 & 73.22 & 5.27 & \multirow{5}{*}{3.77} & \multirow{5}{*}{0.01} \\
\hline & Associate Professor & 29 & 73.15 & 7.24 & & \\
\hline & Professor & 13 & 73.12 & 7.63 & & \\
\hline & Non - Teaching & 10 & 75.45 & 6.22 & & \\
\hline & Students & 8 & 73.78 & 7.78 & & \\
\hline \multirow{4}{*}{ Educational Qualification } & Diploma & 15 & 77.23 & 4.44 & \multirow{4}{*}{7.44} & \multirow{4}{*}{0.01} \\
\hline & Under Graduate & 26 & 74.22 & 7.98 & & \\
\hline & Post Graduate & 22 & 75.12 & 8.66 & & \\
\hline & Professional & 37 & 71.94 & 4.46 & & \\
\hline \multirow{4}{*}{ Experience } & Below 5 & 33 & 77.45 & 7.31 & \multirow{4}{*}{3.24} & \multirow{4}{*}{0.01} \\
\hline & 5 to 10 & 37 & 72.46 & 4.65 & & \\
\hline & 10 to 15 & 18 & 74.21 & 6.41 & & \\
\hline & Above 15 & 12 & 75.55 & 7.22 & & \\
\hline \multirow{2}{*}{ Place of Residence } & Rural & 25 & 71.33 & 6.56 & \multirow{2}{*}{2.22} & \multirow{2}{*}{0.05} \\
\hline & Urban & 75 & 74.45 & 5.45 & & \\
\hline
\end{tabular}

Hy: There is a basic differentiation concerning the customers air of cutting edge library dependent on section factors.

The table shows that the decided t-regard (2.95) which is enormous exhibits that there is a basic differentiation concerning the customers aura of cutting edge library dependent on sex. The table shows that the decided F-regard (4.96) which is tremendous exhibits that there is a colossal qualification concerning the customers attitude of cutting edge library dependent on age. The table shows that the decided F-regard (3.77) which is enormous exhibits that there is a gigantic difference concerning the customers attitude of electronic library dependent on task. The table shows that the decided F-regard (7.44) which is basic exhibits that there is an immense differentiation as for the customers mien progressed library dependent on educational ability. The table shows that the decided F-regard (3.24) which is basic exhibits that there is an immense differentiation as for the customers attitude progressed 
library dependent on experience. The table shows that the decided t-regard (2.22) which is basic exhibits that there is an immense differentiation concerning the customers mien automated library dependent on spot of living course of action. There is a basic differentiation as for the customers mindset of cutting edge library dependent on section factors. So the communicated hypothesis is recognized.

TABLE 2

RESPONDENTS SATISFIED ABOUT DIGITAL LIBRARY SERVICES

\begin{tabular}{|l|c|c|}
\hline \multicolumn{1}{|c|}{ Opinion } & N & Percentage \\
\hline Yes & 90 & 90.0 \\
\hline No & 10 & 10.0 \\
\hline Total & 100 & 100.0 \\
\hline
\end{tabular}

It is seen from the table that $90 \%$ of the customers satisfied about automated library organizations and $10 \%$ of them frustrated about cutting edge library organizations. Hence prevailing portion of the customers satisfied about cutting edge library organizations.

TABLE 3

USERS OPINION ABOUT THE DIGITAL LIBRARY

\begin{tabular}{|l|c|c|}
\hline \multicolumn{1}{|c|}{ Opinion } & N & Percentage \\
\hline Satisfied & 74 & 74.00 \\
\hline Highly Satisfied & 13 & 13.00 \\
\hline Neutral & 07 & 07.00 \\
\hline Dissatisfied & 03 & 03.00 \\
\hline Highly Dissatisfied & 03 & 03.00 \\
\hline Total & 100 & 100.00 \\
\hline
\end{tabular}

It is seen from the table that $90 \%$ of the customers satisfied about automated library affiliations and 10\% of them baffled about bleeding edge library affiliations. Therefore by and large piece of the customers satisfied about cutting edge library affiliations.

TABLE 4

USERS SATISFIED ABOUT MORE NUMBER OF JOURNALS, ARTICLES AND PERIODICALS AVAILABLE IN THE DIGITAL LIBRARY

\begin{tabular}{|l|c|c|}
\hline \multicolumn{1}{|c|}{ Opinion } & N & Percentage \\
\hline Yes & 95 & 95.00 \\
\hline No & 5 & 5.00 \\
\hline Total & 100 & 100.0 \\
\hline
\end{tabular}

It is seen from the table that $95 \%$ of the clients state fulfilled about more number of diaries, articles and periodicals accessible in the advanced library and just $5 \%$ of the clients state disappointed. Hence greater part of the clients fulfilled about more number of diaries, articles and periodicals accessible in the advanced library. 
TABLE 5

USERS OPINION ABOUT PROVIDED THE HIGH SPEED INTERNET FACILITY

\begin{tabular}{|l|c|c|}
\hline \multicolumn{1}{|c|}{ Opinion } & N & Percentage \\
\hline Satisfied & 61 & 61.00 \\
\hline Highly Satisfied & 14 & 14.00 \\
\hline Neutral & 12 & 12.00 \\
\hline Dissatisfied & 05 & 05.00 \\
\hline Highly Dissatisfied & 08 & 08.00 \\
\hline Total & 100 & 100.00 \\
\hline
\end{tabular}

It is seen from the table that $61 \%$ of the clients state fulfilled, $14.0 \%$ of the clients state profoundly fulfilled, $12 \%$ of the clients state unbiased, $5 \%$ of the clients state disappointed and $8 \%$ of them exceptionally disappointed about rapid web office. Thusly lion's share of the clients fulfilled about rapid web office.

TABLE 6

OPINION ABOUT EXTENT REQUIREMENT THE DIGITAL LIBRARY

\begin{tabular}{|l|c|c|}
\hline \multicolumn{1}{|c|}{ Opinion } & N & Percentage \\
\hline Excellent & 41 & 41.00 \\
\hline Adequate & 22 & 22.00 \\
\hline Fair & 32 & 32.00 \\
\hline Inadequate & 03 & 03.00 \\
\hline Poor & 02 & 02.00 \\
\hline Total & 100 & 100.00 \\
\hline
\end{tabular}

It is seen from the table that $41 \%$ of the customers state marvelous, $22 \%$ of them state adequate, $32 \%$ of them state sensible, $3 \%$ of them state lacking and $2 \%$ of them state poor with respect to degree essential the serious library. Subsequently predominant piece of the customers satisfied about degree essential the mechanized library.

TABLE 7

OPINION ABOUT THE TIME TO SPEND FOR DIGITAL LIBRARY FOR GATHERING INFORMATION

\begin{tabular}{|l|c|c|}
\hline \multicolumn{1}{|c|}{ Time } & N & Percentage \\
\hline 30 Minutes & 17 & 17.0 \\
\hline One hour & 46 & 46.0 \\
\hline Two hours & 19 & 19.0 \\
\hline Three hours & 18 & 18.0 \\
\hline Total & 100 & 100.0 \\
\hline
\end{tabular}

It is seen from the table that $17.0 \%$ of the customers experience 30 minutes to get-together information, $46.0 \%$ of them experience under an hour, $19 \%$ of them experience two hours and $18 \%$ of them experience three hours. As such predominant portion of the customers experience more than 1 hour to social event information. 
TABLE 8

OPINION ABOUT CERTAIN TIME VISIT THE DIGITAL LIBRARY

\begin{tabular}{|l|c|c|}
\hline \multicolumn{1}{|c|}{ Time } & N & Percentage \\
\hline Morning (Before start the classes) & 41 & 41.00 \\
\hline Evening (After classes are over) & 20 & 20.00 \\
\hline Lunch hours & 31 & 31.00 \\
\hline Class hours & 8 & 8.00 \\
\hline Total & 100 & 100.0 \\
\hline
\end{tabular}

The above table shows the bits of knowledge with respect to the customers certain time visit the mechanized library. It is accumulated from the table that $41 \%$ of the customers visit the morning time (before start the classes), 20\% of them visit the night (after classes are done), 31\% of them visit the midday breaks and $8 \%$ of them visit the class hours. Thusly larger piece of the customers visit the serious library morning time before start the classes.

TABLE 9

MENTION THE PROBLEM IN USING THE DIGITAL LIBRARY

\begin{tabular}{|l|c|c|}
\hline \multicolumn{1}{|c|}{ Time } & N & Percentage \\
\hline Inadequate Knowledge & 42 & 42.00 \\
\hline Proper Attitude of Digital Library & 19 & 19.00 \\
\hline Inadequate operate the computer skills & 30 & 30.00 \\
\hline Insufficient of the time & 9 & 9.00 \\
\hline Total & 100 & 100.0 \\
\hline
\end{tabular}

The above table shows the issue in using progressed library. It is derived from the table that $42 \%$ of the customers lacking data, $19 \%$ of them fitting attitude of modernized library, $30 \%$ of them insufficient work the PC capacities and 9\% of them deficient of the time. Accordingly a lot of the customers lacking data issue using the modernized library.

TABLE 10

OPINION ABOUT VISIT THE DIGITAL LIBRARY

\begin{tabular}{|l|c|c|}
\hline \multicolumn{1}{|c|}{ Visit the Digital Library } & N & Percentage \\
\hline Daily & 50 & 50.00 \\
\hline Twice a week & 17 & 17.00 \\
\hline Once is a week & 16 & 16.00 \\
\hline Once in a fortnight & 8 & 8.00 \\
\hline Once in a month & 6 & 6.0 \\
\hline Occasionally & 3 & 3.0 \\
\hline Total & 100 & 100.0 \\
\hline
\end{tabular}

The above table shows the bits of knowledge concerning the customers visit the modernized library. It is gotten from the table that a big part of the customers visit the electronic library step by step, $17 \%$ of them visit the serious library multiple times each week, $16 \%$ of them visit the serious library once in seven days, $8 \%$ of them visit the serious library once in a fortnight, $6 \%$ of them visit the modernized library once in a month and $3 \%$ of them visit the automated library on occasion. Appropriately bigger portion of the customers visit the serious library consistently. 
TABLE 11

OPINION ABOUT PURPOSE OF VISIT THE DIGITAL LIBRARY

\begin{tabular}{|l|c|c|}
\hline \multicolumn{1}{|c|}{ Purpose } & N & Percentage \\
\hline To use e-book & 20 & 20.00 \\
\hline To consult reference material & 12 & 12.00 \\
\hline To consult periodical & 16 & 16.00 \\
\hline To get bibliographic information & 13 & 13.00 \\
\hline To get current information & 11 & 11.00 \\
\hline To get statistical information & 19 & 19.00 \\
\hline To recreation purpose & 9 & 9.0 \\
\hline Total & 100 & 100.0 \\
\hline
\end{tabular}

The above table shows the bits of knowledge with respect to the customers reason visit the serious library. It is inferred from the table that $20 \%$ of the customers visit the to use advanced book, $12 \%$ of them visit the reference material, $16 \%$ of them visit the insight periodicals, $13 \%$ of them visit the bibliographic information, $11 \%$ of them visit the current information, $19 \%$ of them visit the quantifiable information and $9 \%$ of them visit the delight reason. In this way a lot of the customers visit the mechanized library research orchestrated work.

\section{CONCLUSIONS}

Web workplaces should be given to customer organization to propel their knowledge. Separate progressed library hours should be assigned in time tables for understudy. School Staff people some make mien of Digital library for the understudy. By far most of the customers have rebuffed the reprographic organization given by the serious library. One away from behind mutilation of CDs appeared by them inadequacy of duplicating organization. To extend the openness of International journal CDs and Foreign periodicals CDs participation. The school should introduce customer guidance program about cutting edge library to all the understudies. Progressed Library is the inconceivable source to the understudies and teachers to propel their understanding. So the University Grand Commission showed approve more resource for improve the structure workplaces. The serious library should make sure about new arrival of current reports. Cover progressed library advance workplaces should be improved. Customer recommendations enable a library to become disposition of its issues and resolve these in a benefitting way. If these proposal are realized, the customer will have more important appreciation and respect for the piece of cutting edge library and its staff in supporting their academic essentials. This will ensure the full co-action and support of the customers. Who will by then consider the to be library as their own.

The investigation expected to know how customers disposition of modernized library in Engineering College Library, Coimbatore. The model decided for the examination is 100 . They are picked aimlessly. The data were accumulated through survey technique. In the wake of picking the model, the surveys were circled. Further, they were coded illustrated. To test the hypothesis, quantifiable instruments, for instance, Percentage examination, Chi-square test, One-way ANOVA and Independent model t-test were used. In the wake of separating the data, the result found that, a lot of them mindset of modernized library. The result found a lot of the assets utilized mechanized library effectively. Customers went up against various issues using the serious library. In any occasion they experience one hour out of every day in cutting edge library. They are furthermore satisfied about over all show of the automated library. In any case, they need to widen the serious library working hours. 


\section{REFERENCES}

1. Ansari, Mehtab Alam (2003) Digital libraries: needs, technology and benefit, ILA Bulletin, 38(3), pp 22-26.

2. Arms, W. Y. (2000) Digital Libraries. Cambridge MA: The MIT Press.

3. Banerjee, Swapna and Chakrabarty, Biplab (1999), Digital libraries: some issues and perspective, ILA Bulletin 34(3-4), October 1998 to March 1999, pp. 60-63.

4. Borgman (2018). Practical digital libraries: Books, bytes, and bucks. San Francisco: Morgan Kaufman.

5. Borgman, C. (2000). From Gutenberg to the Global Information Infrastructure: Access to information in the networked world. Cambridge, MA: MIT Press.

6. Borgman, C.L. (1999) What are digital libraries? Competing visions. Information Processing \& Management, 35 (3) 227-243.

7. Charles, Busha H. and Stephen, Harter P. 1981. "Research methods in librarianship": Techniques and interpretation, p.212.

8. Cyric, Jiji, Deshmukh, G.R. and Rajalakshmi (2002), Digitization of libraries: in modern era, ILA Bulletin 38(3) pp.68-73.

9. Dhaka, R.P.S. and Arora, Kamlesh (1995), Electronic libraries: A myth or a reality, Annals of library science and documentation. 42(4). pp.152-59.

10. Tefko Saracevic, Marija Dalbello (2018), A survey of digital library education Rutgers University, New Brunswick, New Jersey, In: Proceedings of the American Society for Information Science and Technology, vol. 38, pp. 209-223.

11. Tefko Saracevic, PhD (2017), How were digital libraries evaluated?, School of Communication, Information and Library Studies, Rutgers University, New Brunswick, NJ USA, "Evaluating digital libraries is a bit like judging how successful is a marriage". 